\title{
Factors predicting post-traumatic seizure and epilepsy after traumatic brain injury-A retrospective study in tertiary care center of western Nepal.
}

\author{
Aabishkar Bhattarai ${ }^{1}$, Bikash Jang Kshetri ${ }^{1}$, Bijaya Karki ${ }^{1}$, Naresh Poudel ${ }^{1}$, Suman Adhikari ${ }^{1}$, Balgopal Karmacharya ${ }^{2}$, \\ Nikunja Yogi \\ ${ }^{1}$ Medical Officer, ${ }^{2}$ Associate Professor, Department of Neurosurgery, Manipal College of Medical Sciences, Pokhara, Nepal.
}

Received: June 03, 2020

Accepted: August 07, 2020

Published: September 1, 2020

Cite this paper:

Bhattarai A, Kshetri BJ, Karki B, Poudel N, Adhikari S, Karmacharya B, Yogi N. Factors predicting post-traumatic seizure and epilepsy after traumatic brain injury- A retrospective study in tertiary care center of western Nepal. Journal of Brain and Spine Foundation Nepal. 2020;1(1):5-10.

\section{Correspondence:}

Dr. Aabishkar Bhattarai Medical Officer

Department of Neurosurgery,

Manipal College of Medical Sciences, Pokhara, Nepal.

Email: aabishkar.bhattarai@gmail.com

ORCID: https://orcid.org/0000-0003-3669-1707

\begin{abstract}
Introduction: Posttraumatic seizures are the seizures that arise from traumatic brain injury and brain harm due to physical trauma. This study aims to study various clinic-demographic factors associated with post traumatic seizure in Western Nepal. Methods: A retrospective analytical study was carried out in a tertiary hospital of Nepal to determine factors associated with post traumatic seizures. Various parameters were tested for association with post traumatic seizure using student's t test for quantitative and chi square or Fischer Exact test for categorical variables. All the variables showing significant association were subjected to binary logistic regression. P-value $\leq 0.05$ was considered statistically significant. Results: There were 66 (21.02\%) cases with post traumatic seizure in our study. Univariate analysis showed significant association of fall injury ( $\mathrm{p}=0.004)$, loss of consciousness $(\mathrm{p}=0.001)$, post traumatic amnesia $(\mathrm{p}=0.012)$, severity of head injury (Glasgow coma scale) ( $\mathrm{p}=0.011)$ and depressed fractures $(\mathrm{p}<0.001)$. A binary logistic regression was done amongst parameters with significant association with post traumatic seizure which showed patients with fall injury (OR 3.150, $\mathrm{P}=0.003, \mathrm{CI}=1.473-6.734)$ and depressed skull fractures (OR 26.278, p <0.001, CI= 12.155-56.809) had statistical significant association. Conclusion: Injuries secondary to fall, post traumatic amnesia, loss of consciousness, severity of head injury in terms of GCS and depressed skull fractures were significantly associated with post traumatic seizures in our study. On multiple regression model with adjusted odds of 3.15 (1.473-6.734) and depressed skull fractures with an adjusted odds of 26.278 (12.155-56.809) were significantly associated with post traumatic seizure.
\end{abstract}

Key words: Post-traumatic epilepsy, Seizures, Traumatic brain injury.

\section{Introduction:}

Traumatic brain injury (TBI) is a leading cause of acquired epilepsy. ${ }^{1}$ Seizures are a major complication after TBI, and the development of epilepsy is a major issue for neurotrauma patients. An epileptic seizure is an abnormal excessive or synchronous neuronal discharge from the brain leading to transient signs and symptoms. Epilepsy is a disorder of the brain characterized by an enduring predisposition to generate epileptic seizures and by the neurobiological, cognitive, psychological, and social consequences of this condition. ${ }^{2}$ The definition of epilepsy required two unprovoked seizures, but the updated definition of epilepsy can be met with one unprovoked seizure and 


\section{Bhattarai $A$ et al.: Factors predicting post-traumatic seizure}

high likelihood of another. ${ }^{3}$ Post traumatic seizures (PTS) are the seizures that arise from traumatic brain injury and brain harm due to physical trauma. ${ }^{4}$ It is important to differentiate between posttraumatic seizures (PTS) and post traumatic epilepsy (PTE) as the former is a provoked seizure usually due to head trauma while epilepsy is not. However, it is difficult to differentiate between late PTS and PTE as both terms have been used to describe seizures occurring after head trauma that are believed to be causally related to the trauma itself. Most investigators agree that PTE is to be distinguished from repeated seizures in the early stage following TBI, while the brain is acutely traumatized, inflamed, and metabolically disrupted. Therefore, a common set of definitions of PTS includes an (a) immediate post traumatic seizures, usually defined as those occurring within $24 \mathrm{~h}$ after injury;(b) early posttraumatic seizures, which occur less than one week after injury; and (c) late posttraumatic seizures, which occur more than a week after injury. ${ }^{1,2,5}$ According to Verellen et al., PTS are seizures occurring in the first week after TBI, and are considered to be provoked by head injury. PTE is defined as one or more unprovoked seizures that occur at least a week after TBI. ${ }^{6}$ Since the risk of recurrence after a single late post-traumatic seizure is over $70 \%$, most investigators consider a single late post-traumatic seizure as being sufficient for the diagnosis of PTE. ${ }^{7}$

\section{Methods:}

A retrospective analytical study was carried out in between January 2019 to July 2019 in all cases of head injury admitted to Department of Neurosurgery of Manipal College of Medical Sciences, Nepal to study the factors predicting post traumatic seizure. Patients of all ages and both gender were included in the study. Records form the medical record department were accessed and data were assessed for demographics (age, gender, chronic alcoholism) and clinical or radiological parameters (post traumatic seizure, past history of seizures, loss of consciousness, post traumatic amnesia, mode of injury, admission Glasgow Coma Scale, CT scan findings, surgery ). Post traumatic seizures were taken as any seizure documented in the charts of the patients. Seizure occurring within seven days after injury were labelled as early post traumatic seizure and those occurring thereafter were labelled as late post traumatic seizures. Records of patients follow up in outpatient department was assessed through the departmental computers. Those patients not showing up for follow-up were contacted through their telephone numbers and specific questions were asked to inquire about any episode of seizure like activities following head injury. Those patients not having at least three months follow up in their records or via telephonic conversation due to various reasons like deaths without completing the follow-up schedule or not being able to contact the patients in their provided contact numbers were excluded from the study. Patients with past history of seizure disorder or any other pathologies in the brain apart from TBI at admission were also excluded from the study for the ease of assessment. CT scan were reread by the investigating team and were recorded and thus patients where the records were not available or lost or where CT scan films could not be retrieved in departmental computers or in the medical record departments were also excluded from the study. Various lesions in CT scan were recorded in the chart and head injury was also graded according to Marshall Classification of Traumatic Brain Injury. ${ }^{8} \mathrm{CT}$ scan at admission was used for classifying head injury according to Marshall's classification whenever there were multiple CT scans.

Statistical analysis was done using IBM SPSS 20.0 software. Various parameters were tested for 


\section{Bhattarai A et al.: Factors predicting post-traumatic seizure}

association with post traumatic seizure using student's $t$ test for quantitative variables and chi square or Fischer Exact test for categorical variables. All the variables showing significant association were subjected to binary logistic regression. P-value $\leq 0.05$ was considered statistically significant.

\section{Results:}

During the study period, a total of 384 patients were admitted to the neurosurgical department with a diagnosis of traumatic head injury. Out of these 29 patients had missed or lost CT scan images in their records or departmental computers and 41 patients were excluded for various other exclusion criteria, thus 314 patients were included in the study. There were 66/314 cases with post traumatic seizure in our study of which $21 / 314(6.69 \%)$ were early post traumatic seizures and 45/314 (14.33\%) were late post traumatic seizures. The mean age of the patient with post traumatic seizure were $36.99 \pm 20.813$ and those without post traumatic seizure were $34.96 \pm 21.451$ years. There were 249 males and 65 females in the study. Out of 249 males, 47 (18.9\%) had seizures and out of 65 females, 19 (29.2\%) had seizures. Various clinico-demographic profiles of the patients with and without post traumatic seizures and their associations has been tabulated in Table 1. Forty five $(27.3 \%)$ of patients with fall from height had PTS whereas $120(72.7 \%)$ did not and the difference was statistically significant $(\mathrm{p}=0.004)$. Similarly higher number of patients with LOC $(101,70.6 \%)$ did not have seizure against $42(29.4 \%)$ of those who did $(\mathrm{p}=0.001)$ suggesting statistically significant but negative association with PTS. Post traumatic amnesia (PTA) on the other hand had a positive statistically significant association $(\mathrm{p}=0.012)$ with PTS (Table 1). Forty Two (17.6\%) patient with mild head injury, 14 (38.9\%) cases with moderate head injury and $10(25.0 \%)$ cases with severe head injury had post traumatic seizures and the difference was statistically significant $(\mathrm{p}=0.011)$ which suggested that PTS was less frequently associated with mild head injury (Table 2). Amongst the various radiological lesions in CT head, depressed fracture had a statistically significant association with PTS $(\mathrm{p}<0.001)$ (Table 3).

A binary logistic regression was done amongst all the parameters having significant association with post traumatic seizure (Table 4). Patients with fall injury with an odds of 3.150 had a significant association with post traumatic seizure $(\mathrm{p}=0.003)$ whereas depressed fracture amongst all radiological lesions had statistically significant association with post traumatic seizure. (OR 26.278, $\mathrm{p}=<0.001)$.

\begin{tabular}{|c|c|c|c|}
\hline \multirow[t]{2}{*}{ Parameters } & \multicolumn{2}{|c|}{ Post Traumatic Seizure } & \multirow{2}{*}{$\begin{array}{l}\mathrm{P} \\
\text { Value }\end{array}$} \\
\hline & Yes (66) & No (248) & \\
\hline Age in Years (Mean) & $\begin{array}{l}36.99 \pm 20.8 \\
13\end{array}$ & $\begin{array}{l}34.96 \pm 21.45 \\
1\end{array}$ & 0.493 \\
\hline \multicolumn{4}{|l|}{ Sex } \\
\hline Male & $47(18.9 \%)$ & $202(81.1 \%)$ & 0.068 \\
\hline Female & $19(29.2 \%)$ & $46(70.8 \%)$ & \\
\hline Chronic Alcoholism & $10(20.8 \%)$ & $38(79.2 \%)$ & 0.973 \\
\hline RTA & $18(15.9 \%)$ & $95(84.1 \%)$ & 0.097 \\
\hline Fall & $45(27.3 \%)$ & $120(72.7 \%)$ & $0.004 *$ \\
\hline Assault & $4(10.8 \%)$ & $33(89.2 \%)$ & 0.105 \\
\hline $\begin{array}{l}\text { Post Traumatic } \\
\text { Amnesia }\end{array}$ & $25(30.9 \%)$ & $56(69.1 \% 0$ & $0.012 *$ \\
\hline LOC & $42(29.4 \%)$ & $101(70.6 \%)$ & $0.001 *$ \\
\hline Blunt Trauma & $63(20.9 \%)$ & $238(79.1 \%)$ & 1.000 \\
\hline Penetrating Trauma & $5(16.1 \%)$ & $26(83.9 \%)$ & 0.482 \\
\hline
\end{tabular}

\section{Discussion:}

The incidence of post traumatic seizures varies with the spectrum of severity of the inciting injuries, the time period after the injury and the population age range under study. The incidence has been reported anywhere 
between 2 to $53 \% .^{9,10}$ The incidence of early seizures after TBI is reported to be between $2.6 \%$ and $16.3 \% .^{11}$ In our study the incidence of PTS was 66/314 $(21.02 \%)$, that of early post traumatic was $21 / 314$ $(6.69 \%)$ and that of late post traumatic seizure was $45 / 314(14.33 \%)$. After the first late seizure, $86 \%$ of patients have been reported to develop a second seizure within two years, suggesting the establishment of an epileptogenic process. ${ }^{12}$ In general, approximately $80 \%$ of the patients who develop Post traumatic epilepsy (PTE), have their first seizure onset within the first year post-injury, and more than $90 \%$ by the end of the second year. After the first late onset seizure (>1 wk. from injury), $86 \%$ of patients have reported a second seizure within two years. Several risk factors have also been studied and documented for PTS, including younger age or increasing age from 15 years, family history, depression, chronic alcoholism, increasing injury severity, penetrating injuries, depressed skull fracture, acute intracerebral hematoma (especially subdural hematoma), diffuse cerebral edema, loss of consciousness or amnesia more than 30 minutes etc. $^{9,13,14}$

Table 2. Grades of Head injury Vs Post Traumatic Seizure

\begin{tabular}{lll}
\hline Head Injury Grade & Post Traumatic Seizure & $\mathrm{P}$ \\
& & Value
\end{tabular}

\begin{tabular}{llll}
\multicolumn{3}{c}{ Yes (66) } & No (248) \\
\hline $\begin{array}{l}\text { Head Injury Grade } \\
\text { (GCS) }\end{array}$ & & & $0.011^{*}$ \\
$\begin{array}{l}\text { Mild Head Injury } \\
\text { Moderate Head }\end{array}$ & $42(17.6 \%)$ & $196(82.4 \%)$ & \\
$\begin{array}{l}\text { Injury } \\
\text { Severe Head Injury }\end{array}$ & $10(25.0 \%)$ & $22(61.1 \%)$ & \\
Marshalls CT Grade & & & \\
Grade 1 & $5(11.9 \%)$ & $37(88.1 \%)$ & 0.119 \\
Grade 2 & $58(22.1 \%)$ & $204(77.9 \%)$ & 0.275 \\
Grade 3 & $1(25 \%)$ & $3(75 \%)$ & 1.000 \\
Grade 4 & $1(100 \%)$ & $0(0 \%)$ & 0.210 \\
\hline
\end{tabular}

In our series we studied various clinico-demographic parameters against PTS and found that TBI secondary to fall from height, Post traumatic amnesia, loss of consciousness at the time of injury, severity of injury in terms of GCS, and depressed fractures were the parameters showing statistically significant association with PTS. In our study, $30.9 \%$ patients with post traumatic amnesia developed post traumatic seizures and the result was statistically significant. Also, $29.4 \%$ of patients with loss of consciousness after TBI developed post traumatic seizure which was also statistically significant.

Table 3. Various Radiological Lesions Vs PTS

\begin{tabular}{llll}
\hline $\begin{array}{l}\text { Radiological } \\
\text { Parameters }\end{array}$ & \multicolumn{2}{l}{ Post Traumatic Seizure } & P Value \\
& Yes (66) & No (248) & \\
& 18 & 47 & 0.138 \\
$\begin{array}{l}\text { Subdural } \\
\text { hematoma }\end{array}$ & $\begin{array}{l}(27.7 \%) \\
(72.3 \%)\end{array}$ & \\
$\begin{array}{l}\text { Extradural } \\
\text { Hematoma }\end{array}$ & $8(12.7 \%)$ & $\begin{array}{l}55 \\
(87.3 \%)\end{array}$ & 0.070 \\
Contusions & 32 & $\begin{array}{l}113 \\
(77.9 \%)\end{array}$ & 0.672 \\
Midline Shift & $4(26.7 \%)$ & $11(73.3 \%)$ & 0.745 \\
Depressed & $\begin{array}{l}47 \\
(65.3 \%)\end{array}$ & $\begin{array}{l}25 \\
(34.7 \%)\end{array}$ & $<0.001^{*}$ \\
Fracture & $\begin{array}{l}14 \\
(26.9 \%)\end{array}$ & $\begin{array}{l}38 \\
(73.1 \%)\end{array}$ & 0.253 \\
Craniotomy & &
\end{tabular}

According to Annegers et al., the relative risk of seizures was found to be 1.5 (95\% CI 1.0-2.2) after mild injuries; 2.9 (95\% CI 1.9-4.1) after moderate injuries; and 17.2 (95\% CI 95\% CI 12.3-23.6) after severe injuries. ${ }^{14}$ Our study also showed that mild head injuries were less significantly associated with post traumatic seizures $(\mathrm{p}=0.011)$. In our study, $52 \%$ cases of traumatic brain injuries were due to fall and $27.3 \%$ of total fall associated cases developed post traumatic seizures. The odds ratio for fall injury against PTS after 
adjusting all the other significant variables was 3.150 $(\mathrm{p}=0.003 .95 \% \quad \mathrm{CI}=1.473-6.734)$ which suggests patients with fall injury are almost three times less likely to have PTS in comparison to other causes of head injury. Similarly, $65.3 \%$ of patient with depressed fracture developed post traumatic seizures which is statistically significant with the odds ratio 27.278 which signifies high chances of post traumatic seizures in TBIs with depressed fractures supporting earlier research studies. ${ }^{13,14}$

\begin{tabular}{|c|c|c|c|c|}
\hline Predictors & B & $P$ value & $\begin{array}{l}\text { Odds } \\
\text { Ratio }\end{array}$ & $\begin{array}{l}95 \% \text { CI } \\
\text { for Odds }\end{array}$ \\
\hline Fall Injury & 1.147 & $0.003 *$ & 3.150 & $\begin{array}{l}1.473- \\
6.734\end{array}$ \\
\hline $\begin{array}{l}\text { Depressed } \\
\text { Fracture }\end{array}$ & 3.269 & $<0.001 *$ & 26.278 & $\begin{array}{l}12.155- \\
56.809\end{array}$ \\
\hline
\end{tabular}

Immediate post-traumatic seizures likely occur because the impact from the injury stimulates brain tissue that has a low threshold for seizures when stimulated. Early post- traumatic seizures can be the result of the secondary effects of the head trauma such as cerebral edema, intracranial hemorrhage, cerebral contusion or laceration, alterations in the blood-brain barrier, changes in extracellular ions, excessive release of excitatory neurotransmitters such as glutamate, damage to tissues caused by free radicals, and changes in the way cells produce energy. Late seizures are thought to indicate permanent changes in the brain's structure that are thought to result from neuronal and synaptic loss, aberrant sprouting, and rewiring. ${ }^{15}$

\section{Conclusion:}

Injuries secondary to fall from height, post traumatic amnesia, loss of consciousness at the time of injury, severity of head injury in terms of GCS and depressed skull fractures were the factors significantly associated with post traumatic seizures in our study. On multiple regression model when all the significant factors were adjusted fall injuries with adjusted odds of 3.15 (1.4736.734) and depressed skull fractures with an adjusted odds of 26.278 (12.155-56.809) were significantly associated with PTS.

\section{Refrences:}

1. Lucke-Wold BP, Nguyen L, Turner RC, Logsdon AF, Chen YW, Smith KE, Huber JD, Matsumoto R, Rosen CL, Tucker ES, Richter E. Traumatic brain injury and epilepsy: Underlying mechanisms leading to seizure. Seizure. 2015 Dec;33:13-23. https://doi: 10.1016/j.seizure.2015.10.002.

2. Fisher RS, van Emde Boas W, Blume W, Elger C, Genton P, Lee P, Engel J Jr. Epileptic seizures and epilepsy: definitions proposed by the International League Against Epilepsy (ILAE) and the International Bureau for Epilepsy (IBE). Epilepsia. 2005 Apr;46(4):470-2. https://doi: 10.1111/j.00139580.2005.66104.x.

3. Krauss G. Epilepsy is not resolved. Epilepsy Curr. 2014 Nov-Dec;14(6):339-40. https://doi: 10.5698/1535-759714.6.339.

4. Wagner AK, Miller MA, Scanlon J, Ren D, Kochanek PM, Conley YP. Adenosine A1 receptor gene variants associated with post-traumatic seizures after severe TBI. Epilepsy Res. 2010 Aug;90(3):259-72. https://doi: 10.1016/j.eplepsyres.2010.06.001.

5. Asikainen I, Kaste M, Sarna S. Early and late posttraumatic seizures in traumatic brain injury rehabilitation patients: brain injury factors causing late seizures and influence of seizures on long-term outcome. Epilepsia. 1999 May;40(5):584-9. https://doi: 10.1111/j.1528-1157.1999.tb05560.x.

6. Verellen RM, Cavazos JE. Post-traumatic epilepsy: an overview. Therapy. 2010 Sep;7(5):527-531. https://doi: 10.2217/THY.10.57.

7. Lowenstein DH. Epilepsy after head injury: an overview. Epilepsia. 2009 Feb;50 Suppl 2:4-9. https://doi: 10.1111/j.1528-1167.2008.02004.x.

8. Marshall LF, Marshall SB, Klauber MR, Van Berkum Clark M, Eisenberg H, Jane JA, Luerssen TG, Marmarou A, Foulkes MA. The diagnosis of head injury requires a classification based on computed axial tomography. J Neurotrauma. 1992 Mar;9 Suppl 1:S287-92. Available from:https://globalneuro.org/uploads/files/Marshall_CT_ Score_paper_abstract.pdf. 
9. Frey LC. Epidemiology of posttraumatic epilepsy: a critical review. Epilepsia. 2003;44(s10):11-7. https://doi: 10.1046/j.1528-1157.44.s10.4.x.

10. Angeleri F, Majkowski J, Cacchiò G, Sobieszek A, D'Acunto S, Gesuita R, Bachleda A, Polonara G, Królicki L, Signorino M, Salvolini U. Posttraumatic epilepsy risk factors: one-year prospective study after head injury. Epilepsia. 1999 Sep;40(9):1222-30. https://doi: 10.1111/j.1528-1157.1999.tb00850.x.

11. Najafi MR, Tabesh H, Hosseini H, Akbari M, Najafi MA. Early and late posttraumatic seizures following traumatic brain injury: A five-year follow-up survival study. Adv Biomed Res. 2015 May 11;4:82. https://doi: 10.4103/2277-9175.156640.
12. Haltiner AM, Temkin NR, Dikmen SS. Risk of seizure recurrence after the first late posttraumatic seizure. Arch Phys Med Rehabil. 1997 Aug;78(8):835-40. https://doi: 10.1016/s0003-9993(97)90196-9.

13. Teasell R, Bayona N, Lippert C, Villamere J, Hellings C. Post-traumatic seizure disorder following acquired brain injury. Brain Inj. 2007 Feb;21(2):201-14. https://doi: 10.1080/02699050701201854.

14. Annegers JF, Coan SP. The risks of epilepsy after traumatic brain injury. Seizure. 2000 Oct;9(7):453-7. https://doi: 10.1053/seiz.2000.0458.

15. Payan H, Toga M, Bérard-Badier M. The pathology of post-traumatic epilepsies. Epilepsia. 1970 Mar;11(1):8194. https://doi: 10.1111/j.1528-1157.1970.tb03869.x 